\title{
The effects of cultural intelligence and Vietnamese proficiency on expatriate adjustment in Vietnam
}

\author{
Nguyen Tran Dieu Dang ${ }^{1}$, Nguyen Tran Nguyen Khai ${ }^{1 *}$ \\ ${ }^{1}$ School of Business, International University, Vietnam National University \\ Ho Chi Minh City, Vietnam \\ *Corresponding author: ntnkhai@ hcmiu.edu.vn
}

\begin{tabular}{ll}
\hline \multicolumn{1}{c}{ ARTICLE INFO } & \multicolumn{1}{c}{ ABSTRACT } \\
\hline $\begin{array}{l}\text { DOI:10.46223/HCMCOUJS. } \\
\text { soci.en.11.1.1922.2021 }\end{array}$ & $\begin{array}{l}\text { The expatriate adjustment has been receiving more and } \\
\text { more academic attention due to its increasing importance in } \\
\text { globalization. There are many antecedents and outcomes of } \\
\text { cross-cultural adjustment of expatriates. This research explores } \\
\text { the relationships among Vietnamese proficiency, four }\end{array}$ \\
Received: June $10^{\text {th }}, 2021$ & $\begin{array}{l}\text { dimensions of cultural intelligence, and expatriate adjustment. } \\
\text { The study was conducted with data from 379 expatriates }\end{array}$ \\
Revised: June $18^{\text {th }}, 2021$ & $\begin{array}{l}\text { living/lived in Vietnam. The results reveal that Vietnamese } \\
\text { proficiency and metacognitive cultural intelligence affect } \\
\text { general adjustment indirectly through work and interaction } \\
\text { accepted: June } 21^{\text {st }}, 2021\end{array}$ \\
$\begin{array}{l}\text { Keywords: } \\
\text { general adjustment but not the other two facets. The researcher }\end{array}$ \\
$\begin{array}{l}\text { cultural intelligence; expatriate; } \\
\text { expatriate adjustment; host- } \\
\text { country language proficiency; } \\
\text { Vietnam }\end{array}$
\end{tabular}

\section{Introduction}

As a rule of thumb in the ongoing globalization trend, enterprises increasingly reach out to the world to seek growth opportunities away from their backyards. The internationalization process of firms opens a Pandora box of, yes, various opportunities, but also challenges.

Over and above the apparent trend of globalization, the inbound flow of expatriates coming to Vietnam for work increasing tremendously in the past few years. Incomplete data from The Ministry of Labour, Invalids and Social Affairs reveals that more than 80,000 international assignees are working in Vietnam, coming from more than 60 nations and territories. Vietnam raises up among popular choices to be a destination not only for a short vacation but also for starting a new chapter of life. Despite the slightly low annual income compared to average expatriate's income per annum, "work is less stressful than it was at home for almost $40 \%$ of expats and yet almost half say they are more fulfilled working in Vietnam than they were at home. [...] All in all, $92 \%$ of expats working in Vietnam say they are as happy or happier working here than they were at home." (Vietnam Investment Review, 2018, para. 12) As mentioned in this report, Vietnam has been considered a strong cultural identity through times; about $70 \%$ of expats reported enjoying engaging themselves in the culture despite the acknowledged language barrier. The country is highly appreciated in terms of the ease of finding a job or friends, level of friendliness, career prospect, and satisfaction, work, and leisure, etc., in InterNations' annual report in 2018 (InterNations GmbH, 2018).

Companies are sending more and more of their employees abroad, and individuals are 
also engaging themselves in the expatriation trend of their own will. Hence, the importance of expatriate adjustment is enhanced significantly since global staffing is a costly decision and may contain many potential risks. One fully loaded benefits package for an expatriate could lie anywhere in the $\$ 300,000$ - $\$ 1,000,000$ per year (Black \& Gregerson, 1999). Moreover, the case of expatriation failure could harm the company itself as well as individual expats (Ashamalla, 1998).

A limited number of academic works investigate correlates of expatriate adjustment in the International Business (IB) literature globally, let alone in Vietnam. However, Vietnam has one of the greatest potentials to host and welcome expatriates to the country regarding multiple perspectives from personal finance to human well-being. Consequently, the demand for these studies, especially in Vietnam, is high, and it has been a constant concern for human resource managers. During this study, a few surveyed expats have decided to leave Vietnam because of a low level of cultural adjustment. This research paper will examine relationships among some factors and cultural adjustment in the hope of identifying correlates of this phenomenon, as well as applying multicultural management studies in the Vietnamese context.

\section{Literature review}

\subsection{Expatriate adjustment}

The term expatriate adjustment refers to the degree of comfort of an individual towards a novel cultural environment (Black, Mendenhall, \& Oddou, 1991; Black, 1988). Adjustment happens at two levels: psychological and cross-cultural, also being referred to as socio-cultural adjustment. These two concepts are closely related but are driven by different factors (Searle \& Ward, 1990). According to Ward and Kennedy (1993), psychological adjustment is related to well-being and feelings of satisfaction. In contrast, cross-cultural adjustment mainly discusses "the ability to "fit in" or negotiate interactive aspects of the host culture." Their study (Ward \& Kennedy, 1993) on differences between those concepts indicates that subjective factors such as life changes, locus of control, and homesickness are key drivers of psychological well-being. Contrarily, cross-cultural adjustment is determined by cultural distance, relationships between expat and host country nationals, length of residence, language ability, and cultural separation (Ward \& Kennedy, 1993, 1994). Due to the focus of this research, the term "expatriate adjustment" mentioned in this paper will refer to "cross-cultural adjustment".

Black (1988) proposed that expatriate adjustment should not be considered as a unitary concept but multi-dimensional instead. The proposed model consists of three facets of adjustments: general (environment) adjustment, work adjustment, and interaction adjustment. General adjustment, known as social-cultural adjustment, mentions the degree of psychological comfort regarding different factors of the host country, namely are shopping, local cuisine, and entertainment. Work adjustment is influenced by work-related factors like authority relationships and job responsibilities. Interaction adjustment refers to the frequency and quality of communication and interaction with host-nationals, in this paper, are Vietnamese.

Efforts have been made investigating antecedents and outcomes of expatriate adjustment (Bhaskar-Shrinivas, Harrison, Shaffer, \& Luk, 2005; Hechoanova, Beehr, \& Christiansen, 2003).

Hypothesis 1: Interaction adjustment will have an impact on general adjustment

Hypothesis 2: Work adjustment will have an impact on general adjustment

\subsection{Host-country language proficiency and expatriate adjustment}

According to EF English Proficiency Index report (English First, 2018), 53.12\% of the 
Vietnamese population is able to communicate in English. Despite being considered as a moderate English-speaking nation, it is worth noticing that there is still $46.88 \%$ that cannot speak English. Additionally, even though English has been recognized as a universal lingua franca shared spoken by accumulated 1,132 billion speakers around the world, English as a common language does not ensure effectual communication (Baba, Gluesing, Ratner, \& Wagner, 2004; Henderson, 2005). Peltokorpi (2007, p. 70) discusses in one research that: "Even if expatriates are able to speak in English with local employees, the interpretation of the underlying meaning might vary owing to different cultural norms and/or sociolinguistic orientations. Such differences sometimes remain unrecognized and can result in misunderstandings and errors in decisionmaking".

It is not uncommon to observe an instinctual tendency when people are used to communicating in their native language; henceforth, intentionally or unintentionally, expatriates are excluded from the social network (Peltokorpi, 2008). Straightforwardly, Vietnamese proficiency could potentially be a gate leading to more in-depth cultural experiences for expatriates. Language is considered to be a significant contribution of group identity and a way to access restricted information (SanAntonio, 1987). Expatriates with poor host-country language proficiency are likely to be considered as out-group members either intentionally or unintentionally (Peltokorpi, 2007). Limited host-country language skills can result in limited interactions with host-country nationals, local employees, and a low understanding of the local cultural environment.

Hypothesis 3a: Vietnamese proficiency will have an impact on the mediators, interaction adjustment, and work adjustment

\section{Hypothesis 3b: Meta-cognitive cultural intelligence will have an impact on general adjustment}

\subsection{Cultural intelligence and expatriate adjustment}

Following the train of thought about multiple intelligences initiated by Garner (1993), the construct Cultural Intelligence (CQ) was first developed by Earley and Ang (2003) (Cultural Intelligence: Individual Interactions across Cultures). Cultural intelligence can be defined as the ability to perform and manage effectively in novel and varied cultural environments (Ang et al., 2007). Earley and Mosakowski (2016, p. 140) mentioned: "cultural intelligence is related to emotional intelligence, but it picks up where emotional intelligence leaves off".

CQ has been considered as a multidimensional construct that commonly comprises three to four elements (Earley \& Ang, 2003; Earley \& Peterson, 2004; Thomas et al., 2008). Ang et al. (2007) conceptualize cultural intelligence as a four-factor notion: cognition, metacognition, motivation, and behavior. Cognitive CQ discloses the ability to acknowledge cultural norms, practices obtained from training, education and/or personal encounters. It can also be interpreted as knowledge about cultures in general. Metacognitive CQ discloses the ability to gain and understand knowledge regarding cultures (Flavell, 1979). In other words, meta-cognitive CQ is about having and developing adapting strategies in a new cultural environment. Hence, it can be said that metacognition pays attention to higher-order cognitive activities (Ang et al., 2007). Motivational CQ discloses the ability to manage awareness and energy to assimilate and perform in culturally different contexts. Simply put that this dimension discusses an individual's desire and self-efficacy to integrate culturally. Behavioral CQ discloses the ability to display appropriate verbal and non-verbal behaviors to connect with individuals from novel cultures. Individuals with high behavioral intelligence would be able to make culturally proper behaviors 
and tend to be accepted in groups more easily (Ang et al., 2007).

One suggestion was made that individuals with high CQ are more sensitive to the nuances that occurred in cross-cultural circumstances; consequently, they can avoid making cultural faux-pas and make more appropriate conduct (Thomas \& Inkson, 2008). The links among dimensions as mentioned above, intercultural competencies and expatriate performance and/or adjustment during their assignments are confirmed by previous studies (Johnson, Lenartowicz, \& Apud, 2006; Lee \& Sukoco, 2010; Lin, Chen, \& Yi-chen, 2012; Malek \& Budhwar, 2013; Templer, Tay, \& Chandrasekar, 2006). In line with these researches, two independent groups of academics concluded that self-efficacy and interpersonal skills are positively related to expatriate adjustment (Bhaskar-Shrinivas et al., 2005; Hechoanova et al., 2003). Self-efficacy and interpersonal or relational skills in a diverse cultural environment could be loosely interpreted as dimensions of cultural intelligence.

Hypothesis 4a: Meta-cognitive cultural intelligence will have an impact on the mediators, interaction adjustment, and work adjustment

Hypothesis 4b: Meta-cognitive cultural intelligence will have an impact on general adjustment

Hypothesis 5a: Cognitive cultural intelligence will have an impact on the mediators, interaction adjustment, and work adjustment

Hypothesis 5b: Cognitive cultural intelligence will have an impact on general adjustment

Hypothesis 6a: Motivational cultural intelligence will have an impact on the mediators, interaction adjustment, and work adjustment

Hypothesis 6b: Motivational cultural intelligence will have an impact on general adjustment

Hypothesis 7a: Behavioural cultural intelligence will have an impact on the mediators, interaction adjustment, and work adjustment

Hypothesis 7b: Behavioural cultural intelligence will have an impact on general adjustment



Figure 1. Proposed structural model 


\section{Methodology}

\subsection{Sample and data collection}

The population of interest includes any expatriate who is currently on international assignments in Vietnam, as well as those who have previously had this experience. Data were collected via an electronic survey through convenient and snowball sampling methods. Back translation was used in the questionnaire to ensure the least potential of misunderstanding and misinterpretation that may occur (Edunov, Ott, Auli, \& Grangier, 2018).

In two months, 387 responses were received, of which 379 were valid. Regarding their background, the participants are nationals of 44 countries. Americans account for the highest proportion (21.6\%), followed by UK citizens (17.7\%), French (8.7\%), South Africans (7.7\%), and Australians (6.3\%). Europeans represent the largest population which is $46.9 \%$. 83.4\% of them are self-initiated expatriates, and the rest is classified as company-assigned international assignees.

\subsection{Measures}

\subsubsection{Vietnamese proficiency}

The host-country language proficiency scale was adopted and modified (Selmer, 2006). A total of 05 items was used to assess the ability to use the Vietnamese language, which all were created in negative form. The rating for all items was based on a 07-point Likert scale (1strongly disagree; 4-neither; 7-strongly agree). One sample item is "I cannot manage a conversation in local language" (reverse polarity). After running the reliability test for the Vietnamese proficiency construct, the Cronbach's alpha value is 0.875 (Table 1).

\subsubsection{Cultural intelligence}

The cultural intelligence scale was adopted and modified (Ang et al., 2007). A total of 19 items was used to assess the level of cultural intelligence of each expat. The rating for all items was based on a 7-point Likert scale (1-strongly disagree; 4-neither; 7-strongly agree). One sample item is "I am aware of cultural values and religious beliefs of other cultures." After running the reliability test for all four dimensions of $\mathrm{CQ}$, the Cronbach's alpha values lie in the range of $0.734-0.825$.

\subsubsection{Expatriate adjustment}

The expatriate adjustment level was measured based on a self-aggregated scale from several sources (Black, 1988; InterNations GmbH, 2018; Johnson et al., 2006) with the fundamentals of the theoretical framework from (Black, 1988). A total of 13 items was used to assess the degree of psychological comfort regarding general adjustment, work adjustment, and interaction adjustment. The rating for all items was based on a 7-point Likert scale (1-very comfortable; 4-neither; 7-very comfortable). One sample item is "My personal finance - income versus cost of living." After running the reliability test for all four dimensions of CQ, the Cronbach's alpha values lie in the range of $0.662-0.807$, which indicates a mediocre to good acceptability level (Table 1). 


\section{Table 1}

Reliability test and EFA key results

\begin{tabular}{|c|c|c|c|c|c|c|c|}
\hline \multirow[b]{2}{*}{ Construct } & \multirow[b]{2}{*}{ Code } & \multicolumn{2}{|c|}{ No. of items } & \multicolumn{3}{|c|}{ Statistical results } & \multirow[b]{2}{*}{$\begin{array}{c}\text { Total } \\
\text { variance } \\
\text { explained }\end{array}$} \\
\hline & & Before $^{1}$ & After ${ }^{2}$ & $\begin{array}{l}\text { Cronbach's } \\
\text { alpha }^{3}\end{array}$ & $\mathrm{KMO}$ & $\begin{array}{l}\text { Bartlett's test of } \\
\text { sphericity } \\
\text { significance level }\end{array}$ & \\
\hline $\begin{array}{l}\text { Vietnamese } \\
\text { proficiency }\end{array}$ & LP & 5 & 4 & 0.875 & \multirow{5}{*}{0.821} & \multirow{5}{*}{0.000} & \multirow{5}{*}{$65.025 \%$} \\
\hline Metacognitive CQ & $\mathrm{MC}$ & 4 & 4 & 0.825 & & & \\
\hline Cognitive CQ & $\mathrm{COG}$ & 6 & 6 & 0.792 & & & \\
\hline Motivational CQ & MOT & 5 & 2 & 0.734 & & & \\
\hline Behavioural CQ & $\mathrm{BEH}$ & 4 & 4 & 0.819 & & & \\
\hline General adjustment & GA & 6 & 3 & 0.662 & 0.698 & 0.000 & $47.377 \%$ \\
\hline Interaction adjustment & WA & 5 & 4 & 0.729 & \multirow{2}{*}{0.754} & \multirow{2}{*}{0.000} & \multirow{2}{*}{$69.698 \%$} \\
\hline Work adjustment & IA & 2 & 2 & 0.807 & & & \\
\hline
\end{tabular}

Source: Generated by author

\section{Results}

\subsection{Confirmatory Factor Analysis (CFA)}

The results for eight constructs imply a good model fit: $\chi^{2} / \mathrm{df}=1.906, \rho=0.000$, GFI $=$ 0.895, RMSEA $=0.049(\rho=0.613)$, SRMR $=0.054$, CFI $=0.923$, TLI $=0.910$, and AGFI $=$ 0.869 (Table 2).

In addition to the model fit test, construct validity was also checked. All of the constructs passed the discriminant validity and the convergent requirements (Table 3 ).

\section{Table 2}

Goodness-of-fit (GOF) indices

\begin{tabular}{lccccccccccc}
\hline & \multicolumn{10}{c}{ Goodness-of-fit (GOF) index } \\
\cline { 2 - 11 } & $\chi^{2}$ & df & $\chi^{2} / \mathrm{df}$ & $\rho$ & GFI & RMSEA & SRMR & PCLOSE & CFI & TLI & AGFI \\
\hline CFA & 665.086 & 349 & 1.906 & 0.000 & 0.895 & 0.049 & 0.054 & 0.613 & 0.923 & 0.910 & 0.869 \\
SEM $^{4}$ & 797.513 & 360 & 2.215 & 0.000 & 0.874 & 0.057 & 0.0978 & 0.019 & 0.893 & 0.879 & 0.848 \\
SEM $^{5}$ & 343.982 & 156 & 2.205 & 0.000 & 0.918 & 0.056 & 0.0755 & 0.092 & 0.920 & 0.903 & 0.890 \\
\hline
\end{tabular}

Source: Generated by author

\footnotetext{
${ }^{1}$ After running reliability test and before running exploratory factor analysis (EFA), no items were discarded.

${ }^{2}$ After running reliability and after running EFA, 8 items were further eliminated: LP2, MOT1, MOT2, MOT4, WA1, GA2 and GA6.

${ }^{3}$ Cronbach's alpha values were calculated before conducting EFA.

${ }^{4}$ Original structural equation modelling (SEM) analysis.

${ }^{5}$ Revised SEM analysis after running model diagnostics and discarding 09 items because of considerable standardized residual values.
} 


\section{Table 3}

Construct validity indices

\begin{tabular}{llllllllr}
\hline \multirow{2}{*}{$\begin{array}{c}\text { Construct } \\
\text { validity index }\end{array}$} & LP & COG & MC & BEH & WA & IA & GA & MOT \\
\cline { 2 - 9 } & 0.909 & 0.806 & 0.834 & 0.828 & 0.812 & 0.738 & $\mathbf{0 . 5 7 3}$ & $\mathbf{0 . 6 5 0}$ \\
CR & 0.714 & $\mathbf{0 . 4 1 3}$ & 0.562 & 0.548 & 0.520 & 0.588 & $\mathbf{0 . 3 1 0}$ & $\mathbf{0 . 4 9 4}$ \\
MVE & 0.054 & 0.060 & 0.147 & 0.079 & 0.176 & 0.207 & & 0.227 \\
ASV & 0.011 & 0.027 & 0.057 & 0.048 & 0.176 & 0.164 & & 0.116 \\
\hline
\end{tabular}

Source: Generated by author

\subsection{Hypothesis testing}

Hypothesis 1 and 2 predicted that individuals, who are more adjusted to the working environment as well as interaction in Vietnam, would be likely to have a higher comfort level regarding the general environment. The outcomes reveal these relationships are found to be significant $\left(\beta_{\mathrm{H} 1}=0.328 ; \beta_{\mathrm{H} 1}=0.002 ; \beta_{\mathrm{H} 2}=0.334 ; \rho_{\mathrm{H} 2}<0.001\right)$. Work and interaction adjustment appear to have approximately the same positive effect on general adjustment.

Hypothesis 3a was only partially supported: Vietnamese language proficiency only influences interaction adjustment but not work adjustment $\left(\beta_{\mathrm{IA} \leftarrow \mathrm{LP}}=-0.222 ; \rho_{\mathrm{IA} \leftarrow \mathrm{LP}}<0.001\right)$. The relationship stated in hypothesis $3 \mathrm{~b}$ was found to be insignificant.

Hypothesis $4 \mathrm{a}$ and $4 \mathrm{~b}$ were completely rejected since the construct cognitive cultural intelligence could not fit into the model. Hypothesis 5a, 6b, 7a and 7b were also not supported because of low significance values $(\rho>0.05)$. Hypothesis $5 b$ investigating the effect of cognitive CQ on general adjustment is sustained $\left(\beta_{\mathrm{H} 5 \mathrm{~b}}=-0.201 ; \rho_{\mathrm{H} 5 \mathrm{~b}}=0.017\right)$. Hypothesis $6 \mathrm{a}$ confirmed the positive impacts of motivational $\mathrm{CQ}$ on interaction adjustment and work adjustment $\left(\beta_{\mathrm{IA} \leftarrow \text { MOT }}=0.474 ; \rho_{\mathrm{IA} \leftarrow \mathrm{MOT}}<0.001 ; \beta_{\mathrm{WA} \leftarrow \mathrm{MOT}}=0.175 ; \rho_{\mathrm{WA} \leftarrow \mathrm{MOT}}=0.009\right)$.

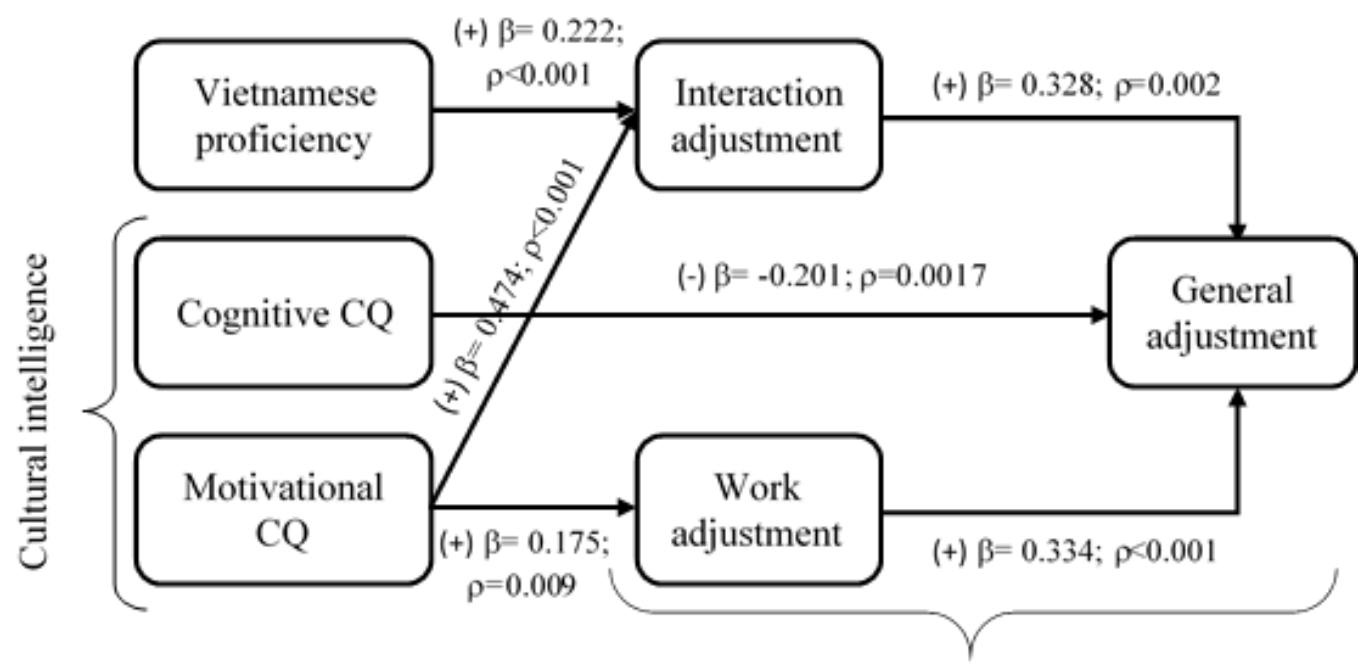

Expatriate adjustment

Figure 2. Revised structural model

\footnotetext{
${ }^{6}$ Thresholds for construct validity measures - CR > 0.7; AVE > 0.5; AVE > MSV; AVE > ASV. Source: Hair, Black, Babin, and Anderson (2014, p. 605)
} 


\section{Discussions}

The purpose of this research is to explore the relationships among host-country language ability, cultural intelligence, and expatriate adjustment. The study proposed that Vietnamese proficiency and four dimensions of cultural intelligence would positively affect three types of adjustment. The findings only provide partial support for the hypotheses, and they are more surprising than anticipated.

The study confirms the influence of language ability on interaction adjustment. It is easier for expatriates to form connections and create their social network in Vietnam if they know Vietnamese beforehand. Vietnamese proficiency allows them to receive more during information exchanges as well as understand more of Vietnamese behavioral norms, traditions and culture, which help them integrate greater into the new living environment. As mentioned in one of Mendenhall and Oddou's article (1985), uncertainty can be decreased, and psychological comfort can also be enhanced by the ability to behave appropriately in terms of culture and predict others' behaviors as well.

The study also supports the findings of (Bhaskar-Shrinivas et al., 2005) that language could, directly and indirectly, affect expatriate adjustment. In addition, this study confirms the number of papers that showed the relationship between cultural intelligence and expatriate adjustment (Hechoanova et al., 2003; Lee \& Sukoco, 2010; Malek \& Budhwar, 2013).

Among the four dimensions of cultural intelligence, the behavior and metacognition side of cultural intelligence did not show any significant impressions on any of the facets of expatriate adjustment. The ability to obtain and adapt cultural strategies, as well as display verbal and non-verbal behaviours are not important for Vietnam-based expatriates. Surprisingly, individuals that scored high in terms of cognitive cultural intelligence are likely to be less adjusted to the general environment in Vietnam. This finding is unique and goes against all of the previous literature. It should be put under consideration. On the other hand, following the results of existing studies, motivational cultural intelligence plays an important role in facilitating adjustment in three facets. This discovery shows that it is crucial to maintain (and enhance) the level of motivation of expatriates throughout their time abroad; otherwise, it could result in a low adjustment, and, eventually, other consequences would appear.

Other researches usually put three facets of cross-cultural adjustment at the same level. However, this paper investigated these relationships at different levels. In brief, the results show that when expatriates adjust to their work and interaction environment, this could affect their comfort towards the general living conditions positively. Also, in line with the research design, the model only explains $5.3 \%$ of work adjustment construct because the independent variables are relatively non-work related. In the meantime, interaction and general adjustment are wellexplained to a limited extent as in a social science study.

\section{Practical implications}

There are no perfect formulas that can guarantee the success of international assignments, if any. It depends on numerous factors coming from the expat him/herself, the company, home country, and host country. Alternatively, this paper recommends that multinational enterprises should pay more attention to host-country language proficiency and cultural adjustment roles.

One suggestion for companies should consider adopting and adapting the cross-cultural training programs that they offer to expatriates. Cross-cultural training could be offered in many forms, such as language lessons, psychotherapy sessions, and cultural knowledge lessons. As proved that knowing the Vietnamese language (language proficiency) could be helpful in the 
adjustment process. Psychotherapy or counseling is also another proposal that possibly enhances self-efficacy and motivational cultural intelligence. As a matter of fact, Earley and Peterson (2004) already published a paper suggesting that cultural intelligence should be integrated into these training programs. Returning to the company's possible takeaway from this research, international human resource practitioners could apply cultural intelligence in their recruitment process for screening and choosing suitable candidates for international assignments.

Through an individual lens, expatriates should also take the initiative themselves if it is not provided by the employer, actively improving Vietnamese level, and self-providing crosscultural training via different ways would assist them in integrating into their culturally novel environment. Additionally, it can be added to the decision-making criteria when one decides on career options and development opportunities.

Another takeaway for academics studying cognitive cultural intelligence, the result may suggest that its effect on expatriate adjustment does not perform the same in different cultures and countries.

\section{Limitations and further research directions}

Limitations of this study need to be taken into consideration when interpreting the findings. First, the scope of this study is bound to a certain degree. The data set from 379 expatriates from 44 countries in Vietnam can only be correctly interpreted in the Vietnamese context. The possibility in this as if more nationalities, especially Asian nationalities, are involved, the result could take another turn. In this population pool, two expatriate types are mixed with each other; as slightly broached, different types of international assignees are believed to be entitled to another set of personality traits that may or may not affect their cultural intelligence index.

Second, data obtained from measurement scales were self-reported. Case in point, items regarding Vietnamese proficiency ask individuals to self-rate how good their Vietnamese is. There were the same for cultural intelligence and expatriate adjustment. Hence, inflationary bias may occur and lead to errors in this study.

Third, cross-cultural adjustment is not a status but rather a process since it is time-related. Longitudinal research design could result in better outcomes. Moreover, the length of the total international assignment, as well as the amount of time that an expat has spent in Vietnam up until the time mark of this study, could also be moderators affecting the proposed relationships.

Fourth, as discussed intensively before, expatriate adjustment is not only affected by language proficiency and cultural intelligence. There are a considerable number of predictors that could be taken into account. Moreover, demographic information such as gender, occupation, marital status, and age could become essential factors in the model as control variables.

Fifth, more studies should be conducted on cognitive CQ to provide a more subjective conclusion on its impact on expatriate adjustment in the Vietnamese context.

\section{References}

Ang, S., Van Dyne, L., Koh, C., Ng, K. Y., Templer, K. J., Tay, C., \& Chandrasekar, N. A. (2007). Cultural intelligence: Its measurement and effects on cultural judgment and decision making, cultural adaptation and task performance. Management and Organization Review, 3(3), 335371. doi:10.1111/j.1740-8784.2007.00082.x

Ashamalla, M. H. (1998). International human resource management practices: The challenge of expatriation. Competitiveness Review, 8(2), 54-65. doi:10.1108/eb046368 
Baba, M., Gluesing, J., Ratner, H., \& Wagner, K. H. (2004). The context of knowing: Natural history of a globally distributed team. Journal of Organizational Behavior, 25(5), 547-587. doi:10.1002/job.259

Bhaskar-Shrinivas, P., Harrison, D. A., Shaffer, M. A., \& Luk, D. M. (2005). Input-based and timebased models of international adjustment: Meta-analytic evidence and theortical extensions. The Academy of Management Journal, 48(2), 257-281. doi:10.5465/amj.2005.16928400

Black, S. J. (1988). Work role transitions: A study of american expatriate managers in Japan. Journal of International Business Studies, 19(2), 277-294. doi:10.1057/palgrave.jibs.8490383

Black, S. J., \& Gregerson, H. (1999). The right way to manage expats. Harvard Business Review, $77(2), 52-63$.

Black, S. J., Mendenhall, M., \& Oddou, G. (1991). Toward a comprehensive model of international adjustment: An integration of multiple theoretical perspectives. Academy of Management Review, 16(2), 291-317. doi:10.2307/258863

Earley, P. C., \& Ang, S. (2003). Cultural intelligence: Individual interactions across cultures. Stanford, CA: Stanford University Press.

Earley, P. C., \& Mosakowski, E. (2016). Cultural intelligence. In H. B. Review (Ed.), HBR's 10 must reads on managing across cultures (pp. 139-145). Boston, MA: Harvard Business Review Press.

Earley, P. C., \& Peterson, R. S. (2004). The elusive cultural chameleon: Cultural intelligence as a new approach to intercultural training for the global manager. Academy of Mangement Learning and Education, 3(1), 100-115. doi:10.5465/AMLE.2004.12436826

Edunov, S., Ott, M., Auli, M., \& Grangier, D. (2018). Understanding back-translation at scale. Retrieved May 21, 2021, from https://arxiv.org/abs/1808.09381

English First. (2018). EF English Proficiency Index Report. Retrived May 21, 2021, from EF EPO Reports database website: https://www.ef.com/assetscdn/WIBIwq6RdJvcD9bc8RMd /legacy/_/ /media/centralefcom/epi/downloads/full-reports/v8/ef-epi-2018-english.pdf

Flavell, J. H. (1979). Metacognition and cognitive monitoring: A new area of cognitive inquiry. American Psychologist, 34(10), 906-911. doi:10.1037/0003-066X.34.10.906

Garner, H. (1993). Multiple intelligence: The theory in practice. New York, NY: Basic Books.

Hair, J. F., Black, W. C., Babin, B., \& Anderson, R. (2014). Multivariate data analysis. Essex, UK: Pearson Education Limited Harlow.

Hechoanova, R., Beehr, T. A., \& Christiansen, N. D. (2003). Antecedents and consequences of employees' adjustment to overseas assignment. Applied pschology: An international review, 52(2), 213-236. doi:10.1111/1464-0597.00132

Henderson, J. K. (2005). Language diversity in international managemeny teams. International Studies of Management and Organization, 35(1), 66-82. doi:10.1080/00208825.2005.11043722

InterNations GmbH. (2018). Expat insider 2018: Continuity versus Change. Retrieved May 21, 2021, from InterNations website: https://www.internations.org/expat-insider/2018/

Johnson, J., Lenartowicz, T., \& Apud, S. (2006). Cross-cultural competence in international business: Toward a definition and a model. Journal of International Business, 37(4), 525543. doi:10.1057/palgrave.jibs.8400205

Lee, L. Y., \& Sukoco, B. (2010). The effects of cultural intelligence on expatriate performance: The moderating effects of international experience. The International Journal of Human Resource Management, 21(7), 963-981. doi:10.1080/09585191003783397 
Lin, Y. C., Chen, A. S. Y., \& Yi-chen, S. (2012). Does your intelligence help to survive in a foreign jungle? The effects of cultural intelligence and emotional intelligence on crosscultural adjustment. International Journal of Intercultural Relations, 36(4), 541-552. doi:10.1016/j.ijintrel.2012.03.001

Malek, A., \& Budhwar, P. (2013). Cultural intelligence as a predictor of expatriate adjustment and performance. Journal of World Business, 48(2), 222-231. doi:10.1016/j.jwb.2012.07.006

Mendenhall, M., \& Oddou, G. (1985). The dimensions of expatriate acculturation: A review. Academy of Management Review, 10(1), 39-47. doi:10.2307/258210

Peltokorpi, V. (2007). Intercultural communication patterns and tactics: Nordic expatriates in Japan. International Business Review, 16(1), 68-82. doi:10.1016/j.ibusrev.2006.12.001

Peltokorpi, V. (2008). Cross-cultural adjustment of expatriates in Japan. The International Journal of Human Resource Management, 19(9), 1588-1606. doi:10.1080/09585190802294903

SanAntonio, P. M. (1987). Social mobility and language use in an American company in Japan. Journal of Language and Social Psychology, 6(3/4), 191-200. doi:10.1177/0261927X8763003

Searle, W., \& Ward, C. (1990). The prediction of psychological and sociocultural adjustment during cross-cultural transitions. International Journal of Intercultural Relations, 14(4), 449464. doi:10.1016/0147-1767(90)90030-Z

Selmer, J. (2006). Language ability and adjustment: Western expatriates in China. Thunderbird International Business Review, 48(3), 347-368. doi:10.1002/tie.20099

Templer, K., Tay, C., \& Chandrasekar, N. A. (2006). Motivational cultural intelligence, realistic job preview, realistic living conditions rreview, and cross-cultural adjustment. Group \& Organization Management, 31(1), 154-173. doi:10.1177/1059601105275293

Thomas, D. C., Stahl, G., Ravlin, E. C., Poelmans, S., Pekerti, A., Maznevski, M., ... Au, K. (2008). Cultural intelligence: Domain and assessment. International Journal of Cross Cultural Management, 8(2), 123-143. doi:10.1177/1470595808091787

Thomas, D., \& Inkson, K. (2008). Cultural intelligence: People skills for global business. Verdana, US: ReadHowYouWant.

Vietnam Investment Review (VIR). (2018). Expats Vote Vietnam among Best Countries to Live and Work. Retrieved May 24, 2021, from https://vir.com.vn/expats-vote-vietnam-amongbest-countries-to-live-and-work-63624.html

Ward, C., \& Kennedy, A. (1993). Psychological and socio-cultural adjustment during crosscultural transitions: A comparison of secondary students overseas and at home. International Journal of Psychology, 28(2), 129-147. doi:10.1080/00207599308247181

Ward, C., \& Kennedy, A. (1994). Acculturation strategies, psychological adjustment and sociocultural competence during cross-cultural transitions. International Journal of Intercultural Relations, 18(3), 329-343. doi:10.1016/0147-1767(94)90036-1 